\title{
THE PHOTOCHEMICAL PRODUCTION OF GOLD SOLS USING ARTIFICIAL LIGHT
}

BY

\author{
F. S. FOWWEATHER
}

From the Department of Chemical Pathology, University of Leeds

(RECEIVED FOR PUBLICATION, DECEMBER 22, 1948)

Twenty years ago (Fowweather, 1928) a method for the preparation of gold sols for the Lange test on cerebrospinal fluids was published in which gold potassium bromide is reduced by potassium oxalate under the action of daylight. Temperature and light intensity were found to be complementary to some extent; thus it was found advisable to carry out the reaction at a somewhat raised temperature in winter, when daylight intensity is comparatively low. Hoess (1931) advocated the use of a "vitalux " lamp, and Herrmann (1935) measured the light intensity by a light meter and adjusted the temperature to the intensity of light. The modifications were not entirely satisfactory, and the search for a satisfactory light source which should be reasonably constant during the course of a preparation continued; two methods were successfully developed during 1940 , and one or other has been in use here ever since. The first uses an ultra-violet lamp and the second a high-power electric lamp of conventional pattern.

\section{Method I}

The lamp used is a Hanovia mercury-vapour lamp of the type used for therapeutic ultra-violet irradiation.

$400 \mathrm{ml}$. of freshly distilled water* is placed in a 500-ml. conical flask having a ground-glass stopper, and the temperature of the water is adjusted to $25^{\circ} \mathrm{C}$. $4 \mathrm{ml}$. of a freshly prepared 1 per cent solution of potassium oxalate ("AnalaR") is added, followed by $6 \mathrm{ml}$. of a 1 per cent solution of gold potássium bromide, and the contents of the flask are thoroughly mixed. (The latter solution need not be freshly prepared, provided it has been kept in the dark in a tightly stoppered bottle, but it is inadvisable to use solutions more than a month old.)

The flask is placed on a bench and the height of the lamp is adjusted so that the mercury tube is

\footnotetext{
* It is not necessary to use doubly distilled water: the importan point is that water should be freshly distilled (Herrmann, 1932).
}

opposite the middle of the flask, and the distance of the tube from the centre of the flask is 11 in. It is probable that the most satisfactory distance between lamp and flask varies with the lamp used, so that the correct distance for any particular lamp should be determined by experiment. Immediately behind the flask is an upright three-piece wooden screen with short centre-piece parallel to the mercury tube, and longer wings fixed at each end at an angle of $135^{\circ}$. This is painted white, and its purpose is to reflect the rays falling on it from the lamp inwards to the flask. As irradiation of the flask proceeds, the brown colour of the solution fades, and after about 12 minutes the solution is colourless. Then red streaks appear and spread through the solution, and soon the typical gold sol is fully developed, the total irradiation period being about 18 minutes. The flask is then placed in diffuse daylight for 3 or 4 hours, after which it is stored in the dark for 2 or 3 weeks before being used, following the recommendation of Herrmann (1932).

\section{Method II}

The lamp is a standard Osram 1,000-watt lamp with clear, uncoloured glass. It is used with a white reflector behind it, as well as one behind the flask. The most satisfactory distance between the centre of the lamp and that of the flask was found to be 13 in., and the period of irradiation about 25 minutes. All other procedures are the same as those employed with the ultra-violet lamp.

\section{Discussion}

The sols prepared by the second method are more cloudy than those prepared by the first, and on the whole the first method is preferred. The second was used successfully over a long period when the Hanovia lamp was not available. The sol has recently been successfully prepared in $1,000 \mathrm{ml}$. quantities by the first method (using $1 \mathrm{ml}$. of oxalate solution and $1.5 \mathrm{ml}$. of bromide solution for each $100 \mathrm{ml}$. of water). 
Difficulties caused by undue stability of sols prepared by these methods have not been met, though there is some evidence that these would occur if sols were still employed more than about three weeks after they have first been brought into use. It is advisable, therefore, to prepare only such quantities as will be used within this period. Occasionally sols are produced that are too sensitive and show a change with normal cerebrospinal fluid, usually of one or two degrees, in the second and third tubes of the Lange test range. Such sols are produced more frequently by the second method than by the first-an additional reason for preferring the latter. This sensitivity can, however, be removed by heating the sol to about $90^{\circ} \mathrm{C}$. and then allowing it to cool. Hence, whenever a new batch is to be brought into use a Lange test on a normal cerebrospinal fluid is made, and this treatment is applied if undue sensitivity is shown.
Sols prepared by the methods described ate equally suitable for cerebrospinal fluid or serum colloidal gold tests.

If a transparent silica flask is used instead of ${ }_{a}^{s_{a}}$ glass flask, the period of irradiation is shortened considerably in the first method, but is not appi․․ ciably altered in the second. Silica transmits ultrâviolet light much better than glass, and it woudd appear, therefore, that in the first method toje ultra-violet light plays a considerable part in the reaction, while in the second it is only visible light which is present and is effective. Hence the range of light frequencies capable of bringing about the reduction of the gold salt by potassium oxalateds not a very narrow one, since it includes part of the visible as well as the ultra-violet portion of the spectrum.

\section{REFERENCES}

Fowweather, F. S. (1928). Brit. J. exp. Path., 9, 161.

Herrmann, W. (1932). Klin. Wschr., 1, 902.

Herrmann, W. (1935). Z. Immunität., 84, 279.

Hcess, H. (1931). Klin. Wschr., 2, 1538. 